\title{
Infant Mortality Among German Settlers in the Nineteenth-Century Russian Empire
}

\author{
Stuart Gietel-Basten \\ The Hong Kong University of Science and Technology \\ Georgia Verropoulou \\ University of Piraeus \\ Rachel Ganly \\ The University of Hong Kong
}

October $25^{\text {th }} 2018$

\begin{abstract}
Currently, very little is known about regional patterns of infant mortality rates [IMR] - or mortality more generally - in the Russian Empire during, and before, the mid-nineteenth century. In particular, what studies have been performed generally rely on the reproduction of aggregate statistics, rather than being based on individual-level data.

The objective of this study is to (a) identify the extent to which registration is complete in a part of the historical Russian region of Bessarabia for the period 1833-1885 and, then, (b) identify trends of IMR in a part of the historical Russian region of Bessarabia for the period 1833-1885. The study utilises church records of births $(\mathrm{N}=21,984)$ and deaths $(\mathrm{N}=7,194)$ from the German colony of Glückstal, a village near modern-day Grigoriopol in Transnistria (Moldova). Three methods of calculating IMR are performed. While there appears to be a significant degree of under-reporting of births which is inconsistent over time as well as gaps in the data more generally, it is possible to account for much of this through adjustment post linkage. After accounting for this, a linked net IMR can be generated. The range over the period is around 100-190, with some periods of crisis mortality. These figures are lower than has been reported for the region. The comparison of different methods of calculating IMRs suggest that birth registration may be incomplete, however. This means that nominative linkage is required to derive accurate rates and other statistics. The findings challenge the widely held view of very high IMRs across the Russian Empire in the nineteenth century. By utilising appropriate methods, this analysis suggests that such colony church records may represent a valuable source for further analysis of this neglected period in Russian demographic history.
\end{abstract}

\section{Introduction}

Trends in infant mortality in Europe followed a variety of pathways from and to different levels. At the turn of the twentieth-century, for example, infant mortality rates [IMRs] were still high, albeit with a high degree of variation across Europe. For example, while IMRs in Norway and Sweden were around 100 deaths per 100 live births around 1900, figures as high as 200 or even 250 were seen in parts of Germany and Austria (Corsini and Viazzo 1993). Meanwhile, at the sub-national level such variation was even higher.

While the transition from high to low infant mortality in the twentieth-century has been well studied, fewer studies have sought to examine long-run trends over the nineteenth-century and before. Such studies have come to divergent conclusions about the shape of the trend over time - not least because of different socioeconomic, climatic, environmental and policy 
contexts. In Sweden, for example, IMR fell in an almost linear fashion from 1900 through to the middle of the twentieth-century (Brandstom 1993). In England and Wales, meanwhile, the rates stayed remarkably constant at around 150 infant deaths per 100 live births over the entire nineteenth-century, before declining sharply after the turn of the twentieth-century (Woods, Williams and Galley 1993) (although this does, of course, mask sharp regional and socioeconomic differences, see Woods, Williams and Galley 1993 and Wrigley et al. 1997 for England; Gehrmann 2011 for Germany).

The orthodox view for the nineteenth-century Russian Empire, however, is that it experienced worse mortality conditions than other European settings, with only modest declines in infant and childhood mortality reported at the very end of the century. A quote typical of this view is as follows: 'Between 25 and 30 per cent of all infants born in the European provinces of the empire in the last third of the nineteenth century died before they were a year old: an infant mortality rate of 250-300 per thousand live births... The death rate among infants and children under five seems to have been at a similar level in the rest of the nineteenth century and, in all likelihood, in earlier times' (Moon 1999, p. 25).

However, this orthodox view is problematic in three ways.

Firstly, it masks substantial heterogeneity within the European provinces of the Russian Empire in the later nineteenth-century. According to Patterson (1995), for example, the infant mortality rate (deaths in the first year per 1000 live births) in the period 1867-81 ranged from below 150 in Vilna province through 200-250 in most of modern-day Ukraine up to over 400 in Moscow. Secondly, the data upon which these figures are calculated may not be consistent either across space or time. In particular, we know that different religious groups adopted different patterns of registration which can affect the relationship between the numerator and the denominator. Thirdly, the period before 1867 is extremely poorly understood, not least because of a lack of consistent mortality reporting across the empire. This leads Dennison and Nafziger (2007) to remark that 'information on health conditions in pre-1861 rural Russia is almost entirely lacking' (see, also, Dennison and Nafziger (2013). Indeed, this final quote points to the scarcity of information about health in nineteenth-century Russia more generally; although evidence from the later nineteenth-century suggests that there was higher infant mortality in the summer months (e.g. Patterson 1993).

Bessarabia was a province of the Russian Empire bordering the Black Sea, roughly sharing the same borders as modern-day Moldova. According to Rashin (1956), infant mortality rates in Bessarabia were somewhat lower than the regional average in 1867-81 at 177. However, these rates increased to 181 by $1886-1897$ and 196 by $1908-1910$.

In many parts of the Russian Empire, settlers from other parts of the world established 'colonies', bringing with them cultural, social and religious traditions (Bartlett 1979) (although these colonists were later the victims of land expropriation, purges and violence, see for example Lohr 2003, and Rempel 1932). In Bessarabia, a number of colonies were established by settlers from Germany. In Glückstal, a village near modern-day Grigoriopol in Transnistria (Moldova), Lutheran settlers predominantly came from Wuerttemberg in Germany in the very early nineteenth century (for an early history of the colony, see Rapp (1848). Some of these colonies appear to have maintained high-quality registers of births, marriages and deaths for an extended period of time well before the late $1860 \mathrm{~s}$. The presence of death date and comprehensive information regarding parents means that it is possible to produce a long-term run of infant mortality rates (1833-85 for Glückstal) using a consistent 
methodology which can detect and partially control for aspects of under-registration. Furthermore, apparently precisely recorded dates of deaths allow for investigation as to the extent to which the nature of infant mortality changed in the first year of life over the nineteenth century, potentially illuminating aspects of changes in health.

Using data from the Glückstal colony, it is then possible to generate estimates of infant mortality for a region of the Russian Empire in the mid- to late- nineteenth century. To reiterate, the value of these estimates is based on (a) the dearth of reported IMRs for the period prior to 1861 - especially for a largely rural area; and (b) the ability to systematically produce transparent IMRs based upon nominative linkage at the micro-level, rather than relying on printed macro-level data.

\section{Data and Methods}

\section{Data}

The data used in this analysis is publicly available via an internet repository (odessa3.org 2018). Transcribed data for births and deaths for the period 1833-1885 were made available. In total, there are 20,985 birth records for the period, and 7,194 death records.

\section{Calculating overall infant mortality rates}

There are numerous methods to calculate infant mortality rates [IMR]. The first is the so-called crude, or gross IMR. This is simply taken as the number of deaths below age one divided by the total number of births multiplied by 1000 . This procedure can be performed simply using aggregate figures to produce what is referred to as the 'conventional infant mortality rate', or $C I M R$. In equation terms this would be:

$$
\operatorname{cIMR}=\frac{D_{o}}{B} \times 1000
$$

\section{Calculating linked, adjusted infant mortality rates}

These figures have been used in many contemporary and historical studies if infant mortality (e.g. Huck 1995). However, while intuitive, the $c I M R$ (and related neonatal and post-neonatal mortality rates) have two distinct limitations, which are aggravated when exploring populations with the possibility unstable birth numbers and/or possible under-registration.

The first issue is that while registration of deaths are usually reliable, registration of births can be less so. This can especially the case for the deaths of infants. Under these circumstances, if the births which are 'related' to the deaths are not recorded, the numerator and denominator are not equivalent and, hence the infant mortality rates will be inflated. Given that under-registration for children dying at very young ages can be especially high, this can therefore have a highly skewing effect on the cNMR.

In order to identify, and therefore correct for under-registration, it is necessary to perform a nominative linkage exercise. This procedure has been applied in numerous studies of historical infant health and mortality, including Basten (2008) and Williams (1992) for Northern England, Mühlichen and Scholz (2015) for Germany, Jaadla and Puur (2015) for Estonia, and so on. While different studies employ different procedures, this study follows Basten (2008) as follows: 
- Input all fields in birth and death registers into spreadsheets and compile database in MS Access

- Perform data cleaning by, for example, standardising dates, transforming age at death into number of days,

- Standardise names through a series of SQL queries linking to look-up tables. This is performed in two separate methods: firstly, by 'human' standardisation, which is a 'light touch' means of manually correcting and standardising names (e.g. Smith, Smithe, Smyth, Smythe are standardised to Smith).

- Create 'dummy birth dates' in a new column in the death table by calculating the age of infant death in days and subtracting from the date of death.

- Link infant deaths to their respective births. This time-consuming procedure is performed by a series of hierarchical SQL commands in MS Access. Firstly, 'tight' links are sought based upon Child's actual name, both parent's forenames and surnames. The links are then manually checked (and multiple links refined) against dummy vs actual date of birth and other information where possible) and, when verified, the appropriate linked birth ID is inserted into the deaths table, and vice versa. After this, links are made on the standardised names (firstly manual, then SOUNDEX and double metaphone). Then, links become 'looser' until, for example, one is only linking child's forename and surname. This process is essential to account for discrepancies in spelling that the standardisation process misses.

- When the linkage process is exhausted, create 'dummy births' for all non-linked infant deaths

- Create linked and net cIMR as per the equations below. The 'linked' conventional IMR $\left[c I M R_{\text {linked }}\right]$ is simply regards as an interim' measure which indicates the extent to which under-registration is an issue. If, for example, there were complete registration of births and deaths (with no migration), then the linked IMR would be the same as the crude and net IMR. If, however, in the more likely scenario that there is under-registration of births, then the linked conventional IMR will be lower than the crude IMR. Under these circumstances, then, it is necessary to create a net conventional IMR $\left[C I M R_{\text {net }}\right]$ by utilising the dummy births created above. Finally, the differentiation between the three rates can tell us more about the nature of event reporting over time.

$$
\begin{gathered}
c I M R_{\text {linked }}=\frac{\text { linked } D_{0}}{B} \times 1000 \\
c I M R_{\text {net }}=\frac{D_{0}}{B+{ }^{\prime} \text { dummy births' }} \times 1000
\end{gathered}
$$

or, in effect,

$$
c I M R_{\text {net }}=\frac{D_{0}}{B+\left(D_{0}-\text { linked }_{0} D_{0}\right.} \times 1000
$$

\section{Results}

Figure 1 shows the results of the exercise. A few trends are in evidence. Firstly, the gap between the linked IMR and the crude and net IMR shows that a relatively high degree of under-registration is in evidence. After the nominative linkage exercise, on average only $76 \%$ of infant deaths were linked to the respective births. However, this is not consistent over the period (StDev for the period is 18.9 with a range of $41.4 \%$ to $100 \%$.

Comparing the figures for Glückstal with the benchmark regional figures for Bessarabia derived from Rashin (1956), we can see that the figures for this rural area are somewhat 
lower, but within a range to be expected. Also, related to data quality, there are clearly some years where registration failure is apparent. For example, in the late 1860 s, some unrealistic IMRs can be identified. Secondly, the overall IMRs at significantly lower than the widelyheld view of national rates over 200 which some studies have presupposed for this period. The general trend derived from the power regression line is one of a general, steady decline over the period. Despite this, there are clearly years of crisis mortality in the later 1840 s and early 1870 s. In the early 1840 s, for example, a measles epidemic took hold in the colony, while in 1847 a very poor harvest was recorded (Rapp 1848)

\section{Figure 1: Gross, linked and net infant mortality rates, Glückstal Colony, Bessarabia, 1835-1885}

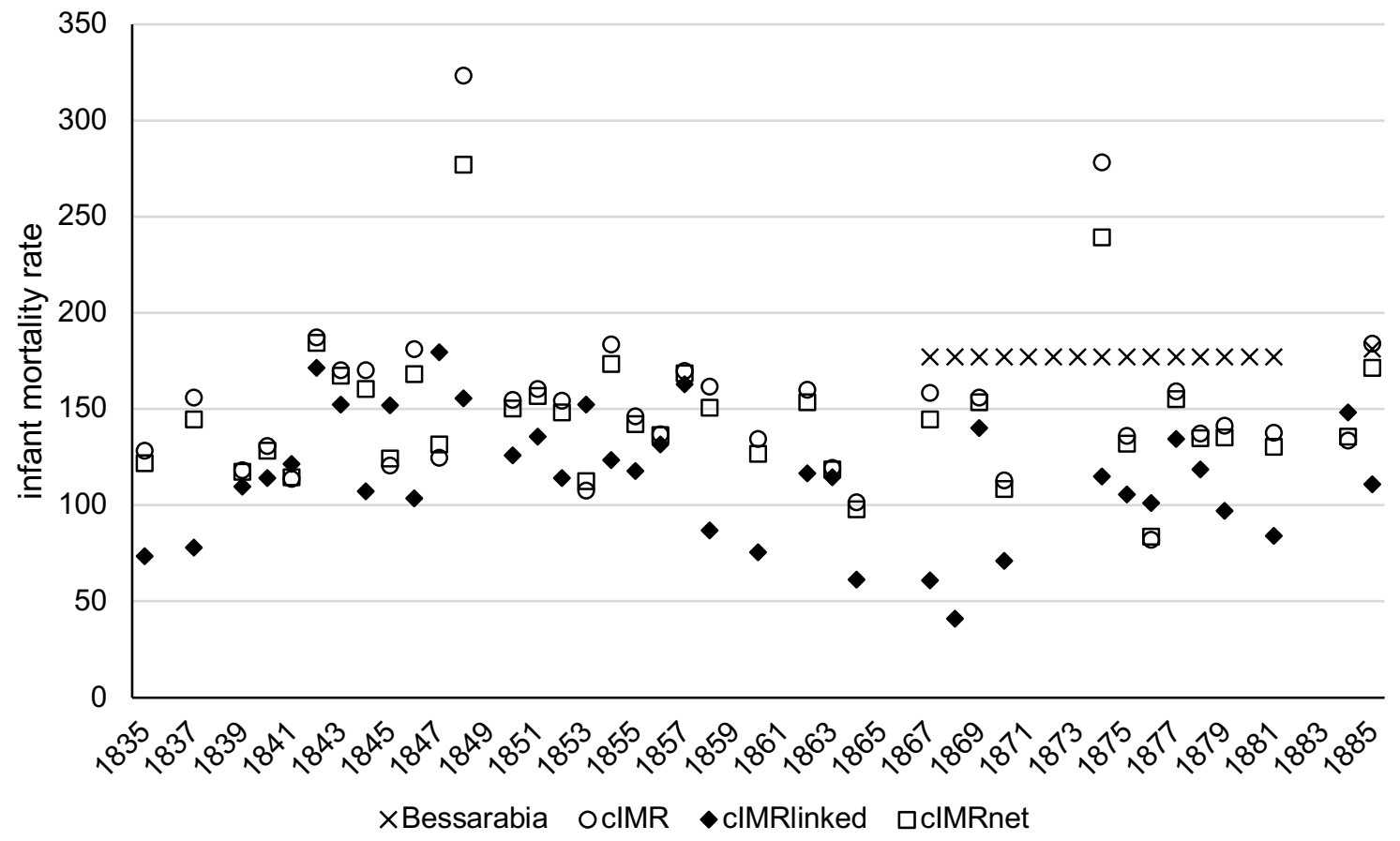

\section{Discussion and conclusion}

This paper presents a very rare estimate of infant mortality in the Russian Empire for the early to middle part of the nineteenth-century. The IMRs presented contrast the widely helped position that Russian IMRs were uniformly high across the Empire and across the nineteenth-century. In fact, these figures for Glückstal appear to be close to those reported for the Province of Vilna in the mid-nineteenth-century, as well as the national figures for England and Wales over the same period. Taken together, then, the evidence presented here further suggests that there may have been a high degree of heterogeneity in the Russian experience of infant mortality over the course of the nineteenth-century.

Methodologically, the figures presented are one of the very first to present a systematic, individual-level analysis based upon the principles of nominative linkage. Importantly, though, the exercise demonstrates the necessity of preforming a nominative linkage exercise rather than relying on calculations derived from crude figures. Furthermore, this exercise is incomplete inasmuch as further calculations related to IMR can (and should be performed); including seasonal variation, reallocation of deaths to appropriate birth year etc. 
However, the presence of other Imperial-era church records in various archives - most notably held in the St Petersburg Archives - points to the possibility of expanding the geographical scope of studying infant health in the nineteenth-century Russian Empire. Furthermore, while this descriptive finding simply presents the overall trends in IMR, more sophisticated statistical and demographic analysis could be performed on this and other data sets to explore further aspects of infant health such as seasonal variations, the changing distribution of first-year mortality and so on. However, the gap between the linked and crude IMRs demonstrate the importance of the performing the (time consuming) nominative linkage exercise especially if further analysis is to be performed. As Patterson (1995) observed his 'reconnaissance' of mortality in late-Tsarist Russia, 'Many questions await research and further studies addressing specific diseases, regions, cities, and ethnic and social groups are essential' (p.179). This short study moves us on a fraction in terms of our understanding of regional trends of IMR in this period; but also in terms of presenting what appears to be a reliable data-set which could be exploited more systematically. 


\section{Bibliography}

Bartlett, R.P. (1979) Human Capital: The Settlement of Foreigners in Russia 1762-1804. Cambridge University Press: Cambridge

Basten, S.A. (2008) Registration practices in Anglican parishes and dissenting groups in Northern England, 1770-1840. Unpublished PhD thesis, University of Cambridge

Brandstrom, A. (1993). 'Infant mortality in Sweden - 1750-1950: Past and present research into its decline' In: Corsini, C. and P.P. Viazzo (eds.) The decline of infant mortality in Europe, 1800-1950: Four national case studies. Unicef: Florence, pp.19-32

Corsini, C. and P.P. Viazzo (1993) 'The historical decline of infant mortality: an overview' In: Corsini, C. and P.P. Viazzo (eds.) The decline of infant mortality in Europe, 1800-1950: Four national case studies. Unicef: Florence, pp.9-18

Dennison, T. and Nafziger, S. (2007) 'Micro-Perspectives on 19th-century Russian Living Standards'. Paper presented at 2007 meeting of the Social Science History Association. See: http://web.williams.edu/Economics/wp/nafzigerMicroLivingStandards_WilliamsWorkingPap er_Nov2007.pdf Date accessed: September $19^{\text {th }} 2018$

Dennison, T. and Nafziger, S. (2013) 'Living standards in nineteenth-century Russia' The Journal of Interdisciplinary History 43(3): 397-441

Gehrman, R. (2011) 'Infant mortality in Germany in the $19^{\text {th }}$ century' Comparative Population Studies 36(4): 839-868

Huck, P. (1995) 'Infant Mortality and Living Standards of English Workers During the Industrial Revolution' The Journal of Economic History 55(3): 528-550.

Jaadla, H. and Puur, A. (2016) 'The impact of water supply and sanitation on infant mortality: Individual-level evidence from Tartu, Estonia, 1897-1900' Population Studies 70(2): 163-179

Lohr, E. (2003) Nationalizing the Russian Empire: The campaign against enemy aliens during World War I. Harvard University Press: Cambridge, MA.

Moon, D. (1999) The Russian peasantry, 1600-1930: the world the peasants made. Routledge: Oxford.

Mühlichen, M. and Scholz, R.D. (2015) 'Demographic analyses of church records: the case of infant mortality in the Hanseatic City of Rostock in the 19th century' MPIDR Technical Report TR-2015-002, 17 pages (May 2015). Max Planck Institute for Demographic Research: Rostock

odessa3.org (2018). St Petersburg Archives: Gluckstal. Available at: http://www.odessa3.org/collections/stpete/gluc/. Date accessed: September $17^{\text {th }} 2018$.

Patterson, K.D. (1999) 'Mortality in late tsarist Russia: A reconnaissance' Social History and Medicine. 8(2): 179-210 
Pozzi, L. and D.R. Farinas (2015) 'Infant and child mortality in the past' Annales de demographique historique 129: 55-74

Rapp, C. (1848). History Of Glücksthal (or Glückstal or Glückstahl or Glueckstal) Available online: http://www.blackseagr.org/pdfs/gluecksthal_history.pdf. Date accessed: September $18^{\text {th }} 2018$

Rashin, A.G. (1956) Russian population for 100 years. State Statistical Publishing: Moscow. (In Russian).

Rempel, D.G. (1932) 'The Expropriation of the German Colonists in South Russia during the Great War' The Journal of Modern History 4(1): 49-59.

Williams, N. (1992) 'Death in its season: Class, environment and the mortality of infants in nineteenth-century Sheffield' Social History of Medicine 5(1): 71-94.

Woods, R., N. Williams and C. Galley (1993) 'Infant mortality in England - 1550-1950:

Problems in the identification of long-term trends and geographical and social variations' In: Corsini, C. and P.P. Viazzo (eds.) The decline of infant mortality in Europe, 1800-1950: Four national case studies. Unicef: Florence, pp.35-50

Wrigley, E.A. et al. (1997) English Population History from Family Reconstitution 15801837. Cambridge University Press: Cambridge 